\title{
Monitoring Drought Trends Induced Climate Variability over Egypt Using MODIS NDVI Satellite Data and Drought Indices
}

\author{
Hossam Ismael*
}

\begin{abstract}
The Drought is considered as a regional phenomenon because the main causes that can produce it are linked to the regional scale. Empirical studies showed that drought is never the result of a single cause. It is the result of many causes, often synergistic in nature (Magaña et al. 1997, Estrada, 2001, Contreras, 2003, Vicente-Serrano et al., 2012, Rita Man Sze Yu, 2013, Joan Ramon, 2013 and Vicente-Serrano et al., 2014). Climatological events over the past three decades have prompted many researchers to pay closer attention to drought across the arid and semi-arid regions such as Egypt. Climate variability leads to more intense and more frequent droughts in the arid regions especially in Egypt. Drought is a recurring extreme climate event over land characterized by below normal precipitation over a period of several months to several years or even a few decades. The main aim of this research is to monitor the drought trends and classification induced by climate variability over Egypt using Terra-MODIS/ NDVI satellite data in companion with Drought Indices. To achieve the aim of the study the climate variability over Egypt is described by the analysis of temperature and rainfall at annual and seasonal time-scale. The drought trends and classifications, which are approached by the application of the most widely, used drought indices Self-Calibrated of Palmer's Drought Severity Index (Sc-PDSI) which improves the "original" PDSI, Standardized Precipitation Evapotranspiration Index (SPEI) which is based on the difference between the precipitation and the reference evapotranspiration, and Standardized Precipitation Index (SPI) which is based on precipitation data over Egypt 19402014. These climatic indices based on rainfall and temperature data, and it has the advantage of combining multi-scalar character with the capacity to include the effects of the temperature variability on drought monitoring. A trend analysis is carried out on drought time-series in order to understand the behavior of drought conditions. Furthermore, the research was depended on the analysis of temperature and rainfall variability from 1940 to 2014 at annual and seasonal timescale. Moreover, the trends and their statistical significance are also analyzed. This analysis provides relevant information related to the behavior of the main climate variables of Egypt under the current climate change conditions. Remote sensing NDVI data provided by Moderate Resolution Imaging Spectroradiometer (MODIS) Sensor, and Terra-MODIS/NDVI data available from 2000 until 2016, it was used to monitor drought in Egypt. The results accentuated that SPEI drought index does not work properly in all stations of Egypt due to the lack of rainfall compared to really high potential evapotranspiration causes an optimal calibration of the index and, in consequence, SPEI will not be a good tool to monitor and analysis dry events in Egypt. In a country like Egypt where reliable data are difficult to obtain continuous, remote sensing data proved to be a significant tool in monitoring and detecting drought components. [Bul. Soc. Géog. d'Égypte, 2016, 89: 91-121]
\end{abstract}

Key Words: climate variability drought conditions, drought index.

* Geography and GIS Department, Faculty of Arts, Assiut University (New Valley Branch), Egypt. 


\section{Introduction}

The sixteen Koppen climate zones can be broadly categorized into "high", "moderate" and "low" based on their overall projected magnitudes of change in drought parameters. The "high" category includes Egypt climate status in BWh, BSh. These climates tend to occur in the low-latitudes around Egypt, and have robust increases in drought. Drought causes major losses in agriculture (Potop et al., 2012 and Hunt et al., 2014) and damages natural ecosystems and forestry (Burke et al., 2008). It may lead to desertification and degradation of soils (Nicholson et al., 1998 and Vicente-Serrano et al., 2012a).

Drought is an insidious natural hazard that results from lower levels of precipitations than what is considered normal. When this phenomenon extends over a season or a longer period of time, precipitation is insufficient to meet the demands of human activities and the environment. The drought must be considered a relative rather than absolute condition. There are also many different methodologies for monitoring drought. Drought is regional in extent and each region has specific climatic characteristics (World Meteorological Organization, 2012).

Climatically, drought is among the most complex climatic phenomena affecting society and the environment (Wilhite, 1993). The root of this complexity is related to the difficulty of quantifying drought severity since we identify a drought by its effects or impacts on different types of systems (agriculture, water resources, ecology, forestry, economy, etc.), but there is not a physical variable we can measure to quantify drought. Thus, droughts are difficult to pinpoint in time and space since it is very complex to identify the moment when a drought starts and ends and also to quantify its duration, magnitude, and spatial extent (Burton et al., 1978 and Wilhite, 2000).

Drought is one of the most damaging natural hazards, in human, environmental and economic terms (Sheffield \& Wood, 2008b and Kirono et al., 2011). It affects agriculture (Dai et al., 2004; Fink et al., 2004 and Motha \& Baier, 2005), irrigation (D“oll, 2002) and food production (Li et al., 2009 and Piao et al., 2014). Droughts also have implications for hydrological (e.g. Groundwater and reservoir storage; Vidal and Wade, 2009) and ecological (Ciais et al., 2005; Gaborone et al., 2005 and Archer \& Predick, 2008) systems, e.g. aquatic ecosystems (Kirono et al., 2011). Their impacts on socioeconomic systems (Alston \& Kent, 2004; Fink et al., 2004 and Ding et al., 2011) include municipal and industrial water supply (Blenkinsop \& Fowler, 2007a and Zhang et al., 2011), hydro-power generation, recreation, industry (Panu and Sharma, 2002), and navigation (Graham et al., 2007). 
Increasing drought conditions can lead to human health concerns (Quevauviller, 2011), e.g. famine in northern Nigeria (Tarhule and Woo, 1997), as they could counteract the effects of the anticipated longer growing seasons.

Despite advances in science and improved technology, drought remains one of the major challenges of climate variability worldwide (Piao et al., 2014). Impact assessment and adaptation decisions require specific information about the spatial and temporal characteristics of drought risk (Loukas \& Vasiliades, 2004 and Mechler et al., 2014). A better understanding of potential future drought evolution could facilitate the implementation of effective adaptation, preparedness and disaster risk reduction measures (Rita Man Sze Yu, 2013).

Drought is one of the main natural causes of agricultural, economic, and environmental damage (Burton et al., 1978; Wilhite \& Glantz 1985 and Wilhite, 1993). Droughts are apparent after a long period without precipitation, but it is difficult to determine their onset, extent, and end. Thus, it is very difficult to objectively quantify their characteristics in terms of intensity, magnitude, duration, and spatial extent. For this reason, much effort has been devoted to developing techniques for drought analysis and monitoring. Among these, objective indices are the most widely used, but subjectivity in the definition of drought has made it very difficult to establish a unique and universal drought index (Mastrandrea, 2014).

It can be summarized, the most prominent of the above, drought is one of the main natural causes of agricultural, economic, and environmental damage, and it is a slow-onset natural disaster, an insidious and creeping phenomenon which occurs in virtually all climatic regimes. It is also related to the timing and the effectiveness of the rains, thus, each drought year is unique in its climatic characteristics and impacts. And also Drought is a major nature hazard affecting large areas and millions of people every year (Burton et al., 1978; Wilhite \& Glantz 1985 and Wilhite, 1993). Droughts are apparent after a long period without precipitation, but it is difficult to determine their onset, extent, and end. Drought is a significant deficiency of precipitation from "normal" over an extended period of time, resulting in a water shortage for some activity, group, or environmental sector. Asia and Africa rank first among continents in the number of people directly affected (EM-DAT, 2008).

For this reason, numbers of indices were developed during the twentieth century for drought quantification, monitoring, and analysis (Du Pisani et al., 1998; Heim, 2002; Keyantash and Dracup, 2002; Joan Ramon, 2013 and Vicente-Serrano et al., 2009, 2010a, 2015). In recent years, there have been 
many attempts to develop new drought indices, or to improve existing ones (Gonza'lez and Valde's, 2006; Keyantash and Dracup, 2004; Wells et al., 2004; Tsakiris et al., 2007 and Vicente-Serrano et al., 2015). Most studies related to drought analysis and monitoring systems have been conducted using either 1) the Palmer drought severity index (PDSI; Palmer, 1965), based on a soil water balance equation, or 2) the standardized precipitation index (SPI; McKee et al., 1993) which based on a precipitation probabilistic approach.

Some studies of drought variability used a few observatories to detect drought conditions across wide regions, highlighting the longevity and the quality of the time-series prior to the density of the network. For example, Szinell et al., (1999) analyzed drought trends in Hungary using 15 long-term stations spread over the country; Briffa et al. (2009) detected dry and wet summers in Europe using 22 long-term series to explain the evidence of increasing drought; Laux et al. (2009) used 29 observatories to demonstrate the precipitation variability in the Volta Basin (West Africa); and Potop (2011) assessed drought variability in the Czech Republic using 15 meteorological stations. Moreover, it is crucial to have time-series as long as possible since this study is focused on drought evolution across time.

In this study, the quantification of drought severity is typically carried out using drought indices, which are proxies based on climatic data; these indices are assumed to adequately quantify the degree of drought hazard for sensitive systems. The development of drought indices has recently been reviewed, and their advantages and drawbacks compared (Heim, 2002; Keyantash \& Dracup, 2002; Sivakumar et al., 2010 and Vicente-Serrano et al., 2011, 2012b, 2014). So, the study used drought indices Self-Calibrated of Palmer's Drought Severity Index (Sc-PDSI) which improves the "original" PDSI, Standardized Precipitation Evapotranspiration Index (SPEI) which is based on the difference between the precipitation and the reference evapotranspiration, and Standardized Precipitation Index (SPI) which is based on precipitation data over Egypt 1940-2014.

Recently, (Drobyshev et al., 2012 and Vicente-Serrano et al., 2011, 2012 b , 2014) analyzed the correlation between different drought indices and fire frequency in Sweden. The results of these studies are diverse, since the best drought index for detecting impact changes as a function of the analyzed system and the performance of the drought indices varied spatially. As a result, at present there is high uncertainty among scientists, managers, and end users of drought information when they aim to select one drought index for a specific purpose (Dongdong Wang et al., 2012). 
Various indices have been developed to depict the drought in different applications (Dracup et al., 1980 and Wilhite \& Glantz, 1985). Among these indices, the standardized precipitation index (SPI; McKee et al., 1993) is the most popular one. SPI has the advantages of flexible time scale and simple calculation procedure. However, SPI also has disadvantages; it only utilizes precipitation information, without considering other meteorological variables that play important roles during the development of a drought event (Taylor et al., 2012 and Teuling et al., 2013). Recently, many attempts have been made to improve SPI by incorporating other Hydrometeorological variables. Vicente-Serrano et al. (2010) developed the standardized precipitation evapotranspiration index (SPEI), defined as the difference between the cumulative precipitation and the cumulative potential evapotranspiration, and found that it is sensitive to the temperature.

\section{Study Area, Data Set and Methods}

\subsection{Study Area}

Egypt lies primarily between latitudes $22^{\circ}$ and $32^{\circ} \mathrm{N}$, and longitudes $25^{\circ}$ and $37^{\circ} \mathrm{E}$, and the country's maximum distances are $1,024 \mathrm{~km}$ from north to south, and $1,240 \mathrm{~km}$ from east to west. It extends over about ten degrees of latitude with the southern portion of the country lying south of the Tropic of Cancer. In consequence most of Egypt comes within Africa's dry desert region, apart from a narrow strip in the far north which experiences a Mediterranean climate. Barren desert covers more than $96 \%$ of the country. The only inhabited part of Egypt is a longitudinal oasis corresponding to the Lower Nile Valley. This locale is where Egypt's inhabitants have concentrated since the dawn of history (Abdel-Kader, 1978).

Egypt is boarded by the Mediterranean Sea to the north, by Sudan to the south, by the Red Sea, Palestine to the east, and by Libya to the west (Figure 1). The total area of Egypt is $1,001,450 \mathrm{~km}^{2}$, with a land area of $995,450 \mathrm{~km} 2$ and a coastline of $3,500 \mathrm{~km}$ on the Mediterranean and the Red Sea. The surface level extremes range from $133 \mathrm{~m}$ below sea level in the Western Desert to 2,629 $\mathrm{m}$ above sea level in the Sinai Peninsula. Climate in Egypt is commonly described as arid and semi-arid, characterized by hot, dry summer, moderate winter and erratic rainfall. According to Koeppen's climate classification, Egypt experiences the 'hot desert climate type' (BWh) in the southern and central parts and the 'hot steppe climate type' (BSh) along the coast. Most parts of Egypt are occupied by the Sahara desert, which represents the most extensive area of severe aridity (Domroes et al., 2005). 


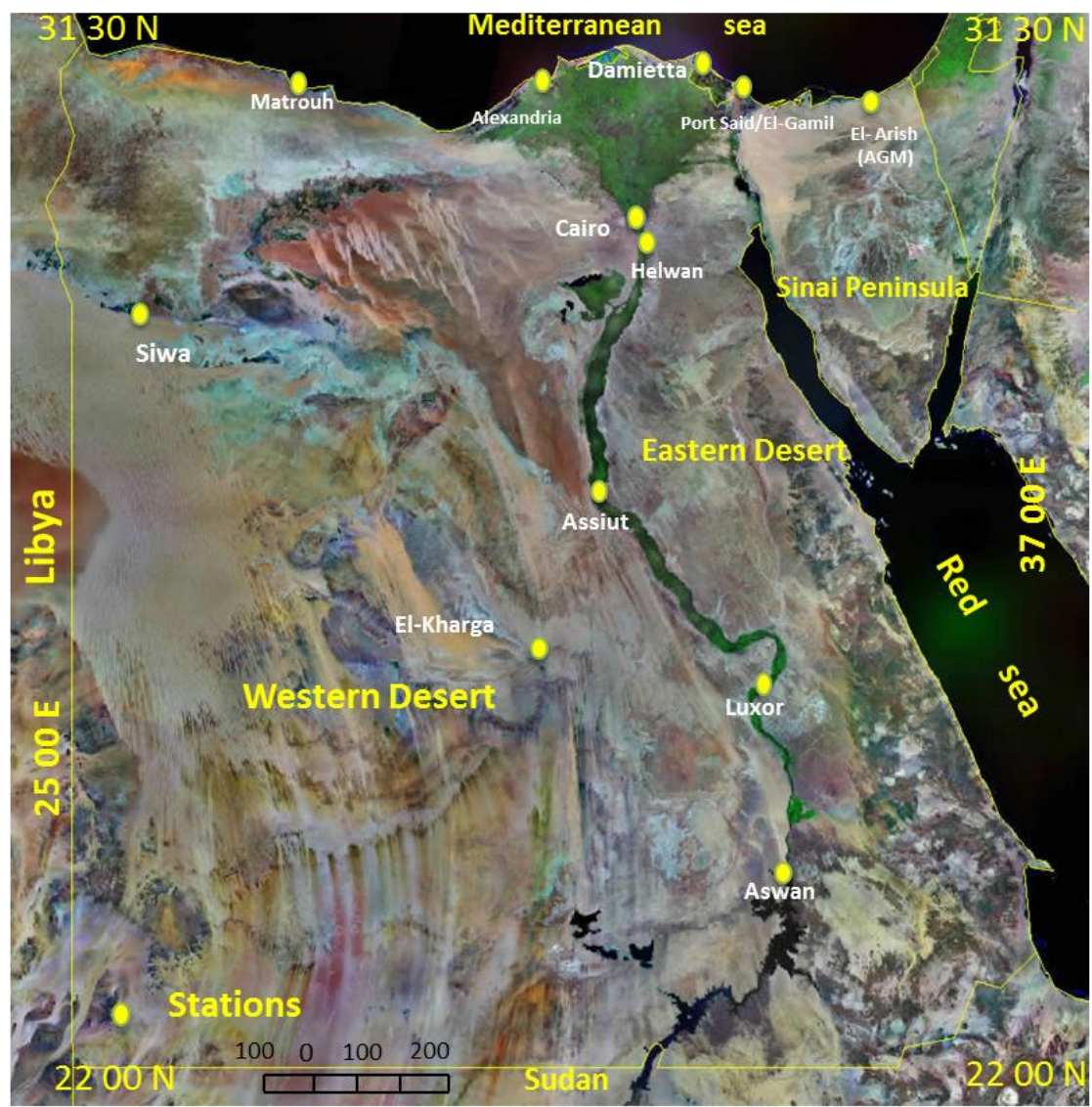

Figure 1. Location map and meteorological stations.

Egypt is located in the hyper-arid regions of North Africa and West Asia astride the Sahara and Arabian Desert with annual rainfall in most parts of less than $50 \mathrm{~mm}$. According to the aridity index P/ETP $(\mathrm{P}=$ precipitation and $\mathrm{ETP}=$ potential evapotranspiration, calculated by Penman's formula), the arid regions are classified to hyper-arid $(\mathrm{P} / \mathrm{ETP}<0.03)$ and arid $(\mathrm{P} / \mathrm{ETP}=0.03-0.20)$. These classes are, in turn, subdivided according to the mean temperature of the coldest month and that of the hottest month of the year. Consideration is also given to the time of the rainy period relative to the temperature regime. On these bases, four climatic provinces in Egypt are distinguished.

Indeed, Egypt faces serious risks from climate change. With $88 \%$ of its water coming from the River Nile and $97 \%$ of its population living along the Nile Delta, a substantial reduction in the flow of the Nile would pose a serious risk to Egypt. In addition, sea level rise (SLR) threatens settlements and agriculture in the Nile Delta and also in the Red Sea. Egypt has been 
already hot and dry. Higher temperatures alone threaten to evaporate more water, increase the need for water supplies, create more heat stress, exacerbate already high levels of air pollution, and drive away tourists. As a result of the above, the drought causes major losses in agriculture and it may lead to desertification and degradation of soils.

In this study, we analyze the trends of droughts induced spatio-temporal climate variability over Egypt between 1940 and 2014, using four climate drought indices. The objectives of the study were as follows: (1) to investigate how the variability of drought has changed across time and how this affects the whole Egypt; (2) to assess trends using different drought indices, considering precipitation droughts and also the influence of warming on drought severity; (3) to analysis drought trends and drought spatial distribution in order to describe the impact of climate change on droughts over Egypt along the $20^{\text {th }}$ century; and (4) to perform an analysis of Spatio-temporal drought analysis based on the combination of duration, severity, area, and inter arrival time using Terra-MODIS/NDVI.

\subsection{Data Set}

We used data series of monthly precipitation $(\mathrm{P})$, and maximum $\left(T_{\max }\right)$ and minimum $\left(T_{\min }\right)$ temperature from 12 meteorological stations, recorded by the Egyptian meteorological authority. The series comprised records of differing temporal length, and included data gaps less than $10 \%$ data. The series were subjected to quality control and homogenization. The quality control procedure was based on comparison of the rank of each data record with the average rank of the data recorded at adjacent stations (Vicente-Serrano et al., 2010a, 2012b) using ACMANT software available at (http://www.c3.urv.cat/data.html).

The current research used Sc-PDSI, the SPI and the SPEI. Temperature and rainfall data from time-series regularly in monthly scale spread Egypt is quality controlled. Rainfall data are only required to compute SPI, but potential evapotranspiration (PET) is also needed to perform the Sc-PDSI and SPEI, which is estimated using the Thornthwaite's method. An interpolation Analysis in Arcgis10.2 is carried out to identify spatial-temporal patterns of drought, the characteristics and trends of severity.

Climatic data were available over the 70 year main period from 1940 until 2014 for the twelve stations: Alexandria, Matrouh, Damietta, Port Said, El-Arish, Cairo, Helwan, Assiut, Luxor, Aswan, Kharga and Siwa (Table 1). The stations under study are scattered across the whole of Egypt, though some parts have a sparse network (Figure 1). The climatic data under study were acquired from the Egyptian Meteorological Authority (www. http://ema.gov.eg) (last visited, 12/08/2015). 


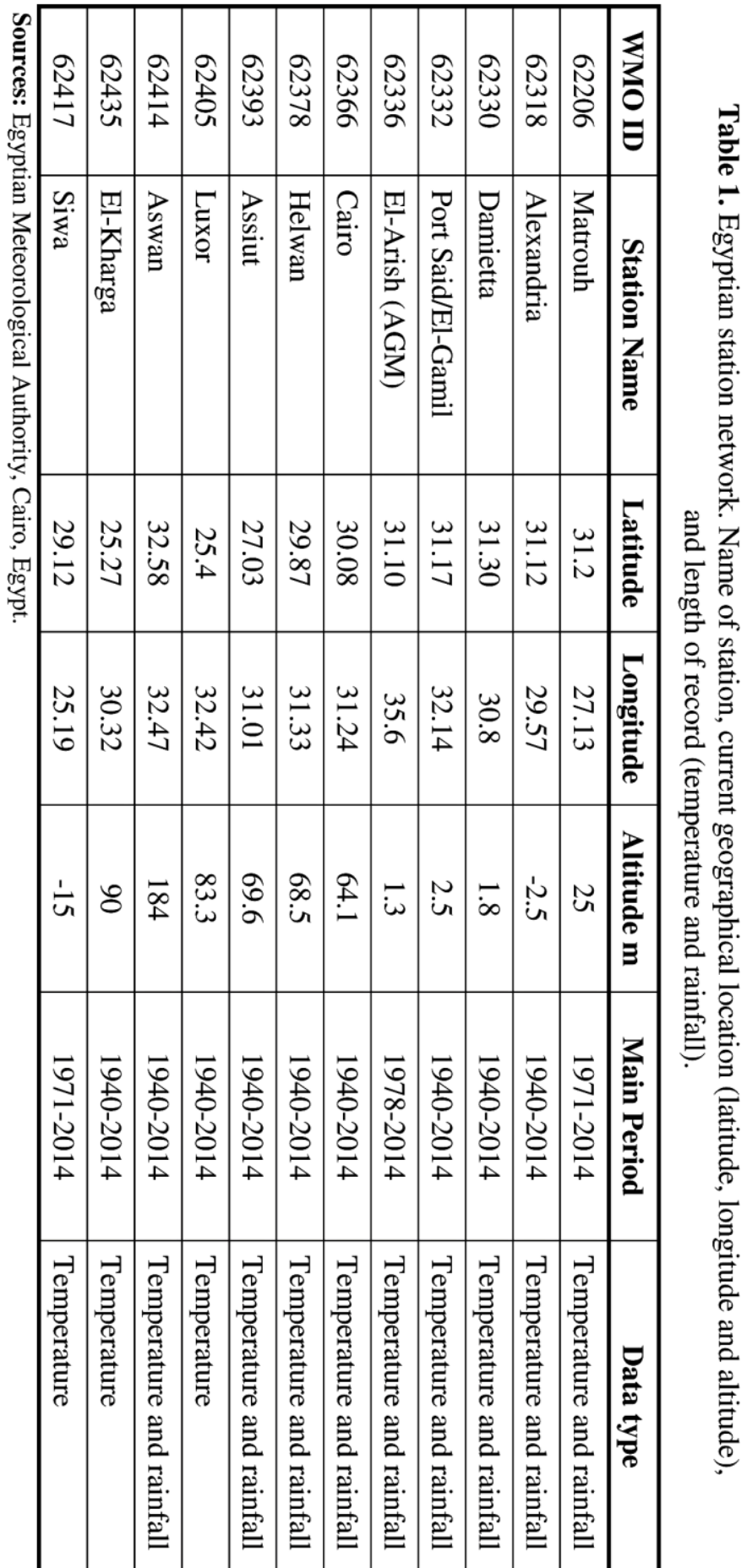




\subsection{Satellite Data}

\section{MODIS/Terra Vegetation Indices (NDVI)}

A complete 16 year, about 4000 available images of daily surface reflectance Moderate Resolution Imaging Spectroradiometer MODIS/Terra data, were used in this study to cover the study area in Egypt. These images were downloaded from National Aeronautics and Space Administration's (NASA) Earth Observing System (EOS), and the website of the Land Processes Distributed Active Archive Center (LP DAAC) using the Warehouse Inventory Search Tool (WIST). Historical surface reflectance and Normalized Difference Vegetation Index (NDVI) products over Egypt are composed in 16-day intervals on the MOD13Q1/250m_16_days_NDVI mapping grid in Geostationary Earth Orbit Tagged Image File Format (GeoTIFF) from February 18, 2000 to April 22, 2016 (http://daac.ornl.gov/modiswebservice $)^{(1)}$.

\subsection{Drought Indices}

Drought indices are important elements of drought monitoring and assessment, since they simplify complex interrelationships between many climates and climate-related parameters. Indices make it easier to communicate information about climate anomalies to diverse user audiences and allow scientists to assess quantitatively climate anomalies in terms of their intensity, duration, frequency and spatial extent (Wilhite, et al., 2000).

\section{The Palmer Drought Severity Index (PDSI)}

The (PDSI) is the most prominent index of meteorological drought used in the United States (Heim, 2002). The PDSI was created by Palmer (1965) with the intent to measure the cumulative departure (relative to local mean conditions) in atmospheric moisture supply and demand at the surface. It incorporates antecedent precipitation, moisture supply, and moisture demand [based on the classic work of Thornthwaite (1948)] into a hydrological accounting system. PDSI values are distributed in 9 categories using a comprehensive classification depending of the severity of dry or wet conditions (Table 2). The PDSI is calculated based on precipitation and temperature data, as well as the local Available Water Content (AWC) of the soil.

(1) The spatial resolution is $250 \times 250$ square meters. For this study, two products were downloaded and analyzed: MCD12Q1 Land Cover Type (Collection 5) and MOD13Q1 Vegetation Indices. MODIS products are provided in HDF-EOS format (Hierarchical Data Format for NASA's Earth Observing System). The standard projection system is a sinusoidal grid projection; MODIS tiles measure 4800 by 4800 pixels, which correspond to about 1200 by $1200 \mathrm{~km}$. NDVI has been used to detect drought in various parts of the world in the recent decades. Normalized difference vegetation index (NDVI), taking the ratio between the difference between the NearInfrared Radiation (NIR) and Visible Red Radiation and their sum. 
Table 2. Classification of PDSI categories defined by Palmer (1965).

\begin{tabular}{|l|c|}
\hline \multicolumn{1}{|c|}{ Categories } & PDSI value \\
\hline Extremely wet & $\geq+4$ \\
\hline Severely wet & $\geq+3$ to $<+4$ \\
\hline Moderately wet & $\geq+2$ to $<+3$ \\
\hline Slightly wet & $\geq+1$ to $<+2$ \\
\hline Near normal & $>-1$ to $<+1$ \\
\hline Slightly dry & $>-2$ to $\leq-1$ \\
\hline Moderately dry & $>-3$ to $\leq-2$ \\
\hline Severely dry & $>-4$ to $\leq-3$ \\
\hline Extremely dry & $\leq-4$ \\
\hline
\end{tabular}

PDSI has been criticized for a variety of reasons of which most significant, perhaps that is not comparable between diverse climatological regions (Alley, 1984 and Karl, 1986). This problem has been solved by Wells et al. (2004) creating Self-Calibrated PDSI (Sc-PDSI) which improves the "original" PDSI. A detailed description of the modifications to this algorithm to obtain the Sc-PDSI is given by Wells et al., 2004 and van der Schrier et al. (2006a).

\section{The Standardized Precipitation Index}

The SPI is based on the conversion of the precipitation data to probabilities, based on long-term precipitation records computed at various time scales. The index has the advantages of being easily calculated, having modest data requirements (only precipitation), and being independent of the magnitude of mean rainfall and hence comparable over a range of climatic zones. It does, however, assume the data are normally distributed, and this can introduce complications for short time periods (Agnew, 2000). The SPI has been accepted by the World Meteorological Organization (WMO) as the reference drought index and it should be used by national meteorological and hydrological services worldwide to characterize meteorological droughts (Hayes et al., 2011). The SPI has been extensively used for drought analysis in many studies (e.g., Hayes et al., 1999; Lana et al., 2001; Vicente-Serrano et al. 2004, 2006, 2008, 2014 and 2011; Mavromatis, 2007; Kingtse et al. 2008, 2009; Dubrovsky et al. 2007b, 2008; Wu et al. 2009; Subash et al. 2014), and has become an important component in many drought monitoring efforts (i.e., the U.S. Drought Monitor (NCDC and NDMC), North American Drought Monitor (NOAA) and European Drought Observatory (EDC).

To calculate the SPI, a long-term precipitation record at the desired station is first fitted to a probability distribution (e.g. Gamma distribution), which is then 
transformed into a normal distribution, so that the mean SPI is zero (McKee et al., 1993, 1995 and Edwards \& McKee, 1997). The SPI may be computed with different time steps (e.g. 1 month, 3 months, 24 months). The SPI may be used for monitoring both dry and wet conditions. The 'drought' part of the SPI range is arbitrarily split into 'near normal' $(0.99>\mathrm{SPI}>-0.99)$, 'moderately dry' $(-1$. $0>$ SPI $>-1.49)$, 'severely dry' $(-1.5>$ SPI $>-1.99)$ and 'extremely dry' (SPI $<-2$. 0) conditions. A drought event starts when the SPI value reaches -1.0 and ends when SPI becomes positive again. The positive sum of the SPI for all the months within a drought event is referred to as 'drought magnitude'. This index is presently used as one of the indices for drought monitoring in the entire United States (http://www.drought.unl.edu/monitor/spi.htm). Also, a number of studies evaluated the performance of this index (e.g. Wu et al. (2001) - in China, Ansari (2003) - in Iran, etc.). The resulting value is the SPI for the particular precipitation data point. SPI can be calculated using the following expression:

$$
\mathrm{SPI}=\mathrm{X}_{\mathrm{ik}}-\mathrm{X}_{\mathrm{i}} / \mathrm{O}_{\mathrm{i}}
$$

$\mathrm{o}_{i}=$ standardized deviation for the station .

$X_{i k}=$ precipitation for the station. $k$ the observation .

$X_{i}=$ mean precipitation for the station

In this study, the current study used the algorithm described by VicenteSerrano (2006), based on the Pearson III distribution and the L-moments approach, to obtain the distribution parameters for calculating the 6-, 12month SPI.

\section{The Standardized Precipitation Evapotranspiration Index}

The main criticism of the SPI is that its calculation is based only on precipitation data. The index does not consider other variables that can influence drought severity, since the SPI relies on two assumptions: (i) the variability of precipitation is much higher than that of other variables, such as temperature and potential evapotranspiration (PET); and (ii) the other variables are stationary (i.e., they have no temporal trend). The importance of variables other than precipitation is negligible in this framework, and droughts are assumed to be mainly controlled by the temporal variability of precipitation. Nevertheless, the role of warming-induced drought stress has been made evident in recent studies that analyzed drought impacts on tree growth and mortality (e.g., Barber et al. 2000; Martı'nez-Villalta et al. 2008; Allen et al. 2010; Carnicer et al. 2011; Camarero et al. 2011; Linares and Camarero 2011) and on water resources (Cai and Cowan 2008; Lespinas et al. 2010; Yulianti and Burn 1998; Liang et al. 2010; Yang and Liu 2011 and Vicente-Serrano et al. 2014). 
The standardized precipitation evapotranspiration index (SPEI) was first proposed by Vicente-Serrano et al. (2014a) (http://cran.r-project.org/web/ packages/SPEI/index.html) as an improved drought index that is especially suited for studies of the effect of global warming on drought severity. Like the Palmer drought severity index (PDSI), the SPEI considers the effect of reference evapotranspiration on drought severity, but the multi-scalar nature of the SPEI enables identification of different drought types and drought impacts on diverse systems (Vicente-Serrano et al., 2012a, 2012b, 2013a, $2013 \mathrm{~b}$ ). Thus, the SPEI has the sensitivity of the PDSI in the measurement of evapotranspiration demand (caused by fluctuations and trends in climatic variables other than precipitation), is simple to calculate, and is multi-scalar, like the standardized precipitation index (SPI). Vicente-Serrano et al. (2014a, 2014b, 2011a, 2011b, 2012a) provided complete descriptions of the theory behind the SPEI, the computational details, and comparisons with other popular drought indicators such as the PDSI (Palmer, 1965) and the SPI (McKee et al., 1993).

The procedure for calculating the SPEI is similar to that for the SPI. However, the SPEI uses "climatic water balance", the difference between precipitation and reference evapotranspiration ( $\mathrm{P}-\mathrm{ET} 0)$, rather than precipitation $(\mathrm{P})$ as the input. The climatic water balance compares the available water $(\mathrm{P})$ with the atmospheric evaporative demand (ET0), and therefore provides a more reliable measure of drought severity than only considering precipitation (Santiago Beguer' et al., 2014). The analysis depended on a simplified equation developed by Hargreaves and Samani (1985), which only requires information on maximum and minimum temperatures, and the extraterrestrial solar radiation. Based on this approach, the ETo (mm day-1) was calculated using the equation:

$$
E T o=0.0023 R_{a} R^{0.5}(T+17.8)
$$

Where $\mathrm{R}$ is the difference between the maximum and minimum temperatures (monthly averages in ${ }^{\circ} \mathrm{C}$ ). $\mathrm{T}$ is the mean monthly temperature and $\mathrm{Ra}$ is the extraterrestrial solar radiation expressed in equivalent evaporation ( $\mathrm{mm}$ day-1), which depends on the latitude and the day of the year.

\section{Results and Discussion:}

\subsection{Annual and Seasonal Temperature Variability}

Climate in Egypt is commonly described as arid and semi-arid, characterized by hot, dry summers, moderate winters and erratic rainfall. According to Koeppen's climate classification, Egypt experiences the 'hot desert climate type' (BWh) in the southern and central parts of the country and the 'hot steppe climate type' (BSh) along the coast. Most parts of Egypt are occupied by the Sahara desert, which represents the most extensive area 
of severe aridity on the globe (Manfred Domroes, et al, 2005). Temperature data of Egypt consist of gridded data for the period 1940-2014. The data were taken from Egyptian meteorological authority, unpublished data. The correlation coefficient was used to test the strength of the temperature relationships with time. Linear trend was used to understand the temperature trends from 1940 to 2014.

Annual temperature anomalies computed from 1940 to 2014 show a clear increasing trend of $0.35{ }^{\circ} \mathrm{C} /$ decade, statistically significant at the $99 \%$ level (Table 3). Annual temperature anomalies computed from 1900 to 2014 show a clear increasing trend of $0.35^{\circ} \mathrm{C} /$ decade, statistically significant at the $99 \%$ level (Table 3). This is consistent with the Egypt temperature increase described by (Manfred Domroes et al., 2005; El-Kadi, 2012 and Climatic Research Unit, University of East Anglia, 2014) for the period 1940-2000. Other regional studies showed a qualitative concordance with this one (e.g. For the interior of Alexandrov, 2006; Castilla-León, del Río et al., 2005; Andalucía, Dolinar et al., 2007; Catalonia, Martínez et al., 2009; Enric et al., 2012 and Joan Ramon, 2012).

Table 3. Linear trends (in ${ }^{\circ} \mathrm{C} /$ decade) computed for annual and seasonal temperature in Egypt (1900-2014). The associated 95\% confidence intervals.

\begin{tabular}{|c|c|c|}
\hline Time-scale & $\begin{array}{c}\text { Linear trend } \\
\left({ }^{\mathbf{}} \text { C/decade) }\right.\end{array}$ & $\begin{array}{c}\text { 95\% confidence } \\
\text { intervals }\end{array}$ \\
\hline DJF (Winter) & $\mathbf{0 . 4 8}$ & $(0.083 / 0.174)$ \\
\hline MAM (Spring) & $\mathbf{0 . 3 5}$ & $(0.066 / 0.190)$ \\
\hline JJA (Summer) & $\mathbf{0 . 4 6}$ & $(0.086 / 0.189)$ \\
\hline SON (Autumn) & $\mathbf{0 . 1 2}$ & $(0.018 / 0.151)$ \\
\hline Annual & $\mathbf{0 . 3 5}$ & $(0.054 / 0.155)$ \\
\hline
\end{tabular}

The observed temperature increase is not constant across time (Figure 2). A first period of warming took place between 1900 and 1928, followed by a short period of decreasing temperatures between 1928 and 1935, and another short period of increasing temperatures between 1936 and 1943. A period of falling temperatures was identified from 1970 to 1988. The warmest years appear between 1994s and 2014s, being 1998 the warmest of the whole Egypt time series. Since 1993, the global average temperature has risen at a rate approximately three times faster than the century-scale trend (Alexandrov, et al., 2004). There was also pronounced decrease in the Northern Hemisphere temperature between 1992 and 2000 (Bertrand and Ypersele, 2002), this decrease was also well apparent in the temperature of Egypt. 
Moreover, seasonal temperature anomalies also show a clear increase of $0.480{ }^{\circ} \mathrm{C} /$ decade for winter (DJF); $0.350{ }^{\circ} \mathrm{C} /$ decade for spring (MAM); 0.462 ${ }^{\circ} \mathrm{C} /$ decade for summer (JJA); and $0.122{ }^{\circ} \mathrm{C} /$ decade for autumn (SON), all statistically significant at the $99 \%$ level (Table 3). Summer and spring are the seasons with the highest rates of change while winter and autumn show lower trends. But, as described for the annual temperature anomalies, the increase is not also constant across time in seasonal temperatures.

Figure (3) represents the seasonal temperature variability over Egypt from 1900 to 2014 using the main period 1940-2000. The trends show a build-up of continuous warming from the beginning of the 1900 to around mid 1950s, followed by a decreasing downward trend to the early 1965s, followed by a stabilization of temperatures between 1965s and 1984 . Therefore the upward and downward cyclic patterns concealed the long-term trends and the resulted correlation and the linear trends were insignificant in the whole period. This finding confirmed the result of (Hasanean, 2004), who concluded that the trends in wintertime temperature of Egypt are not significant at all stations. He found upward warming trends during the 1910s1940s, mid 1970s and from 1980s onwards, and a downward trend occurred during 1950-1960s, showing similar patterns.

Unexpectedly, the variability of spring temperatures is lower than in winter because the first warming period took place between 1939 and 1960, followed by a stabilization of temperatures until 1965. A clear decrease in temperatures was identified from 1962 to 1983 , being the last one the coldest spring of the time-series. Finally, a clear warming period was recorded from 1988 to 1999 , being the last one the warmest spring over Egypt. The last years of the time-series were dominated by a slight decrease of temperatures in spring.

Furthermore, the variability of summer temperature shows a short warming period at the beginning of the time-series, from 1908 to 1920 , followed by a decreasing of temperatures until 1928. As occurred in spring temperatures, another warming period was identified from 1932 to 1960, although the second, decreasing period began in 1964 and prolonged until 1990, being the last one the coldest summer in the time-series.

Since then, a clear warming period was detected until 2014, being the summer of 1998 the warmest summer ever recorded in Egypt with an anomaly of almost $+3.6{ }^{\circ} \mathrm{C}$. Therefore, Summer of Egypt is climatologically characterized by strong warming in the last three decades of the last century. A similar strong tendency of warming was found in Greece, Palestine and Iberian Peninsula (Feidas, et al., 2004; El-Kadi, 2008 and Joen Romon, 2013). 


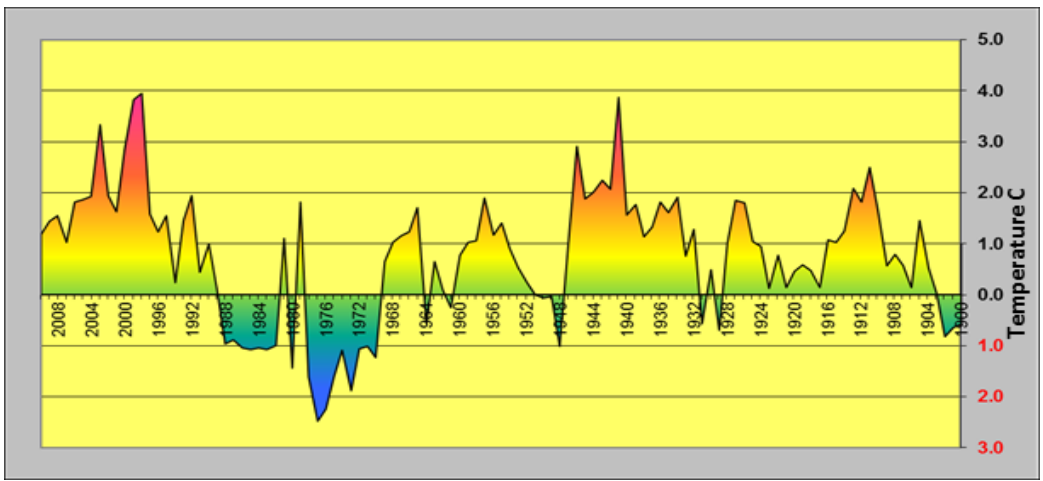

Figure 2. Annual temperature anomalies (base-period 1940-2000) Egypt for the period 1900-2014.

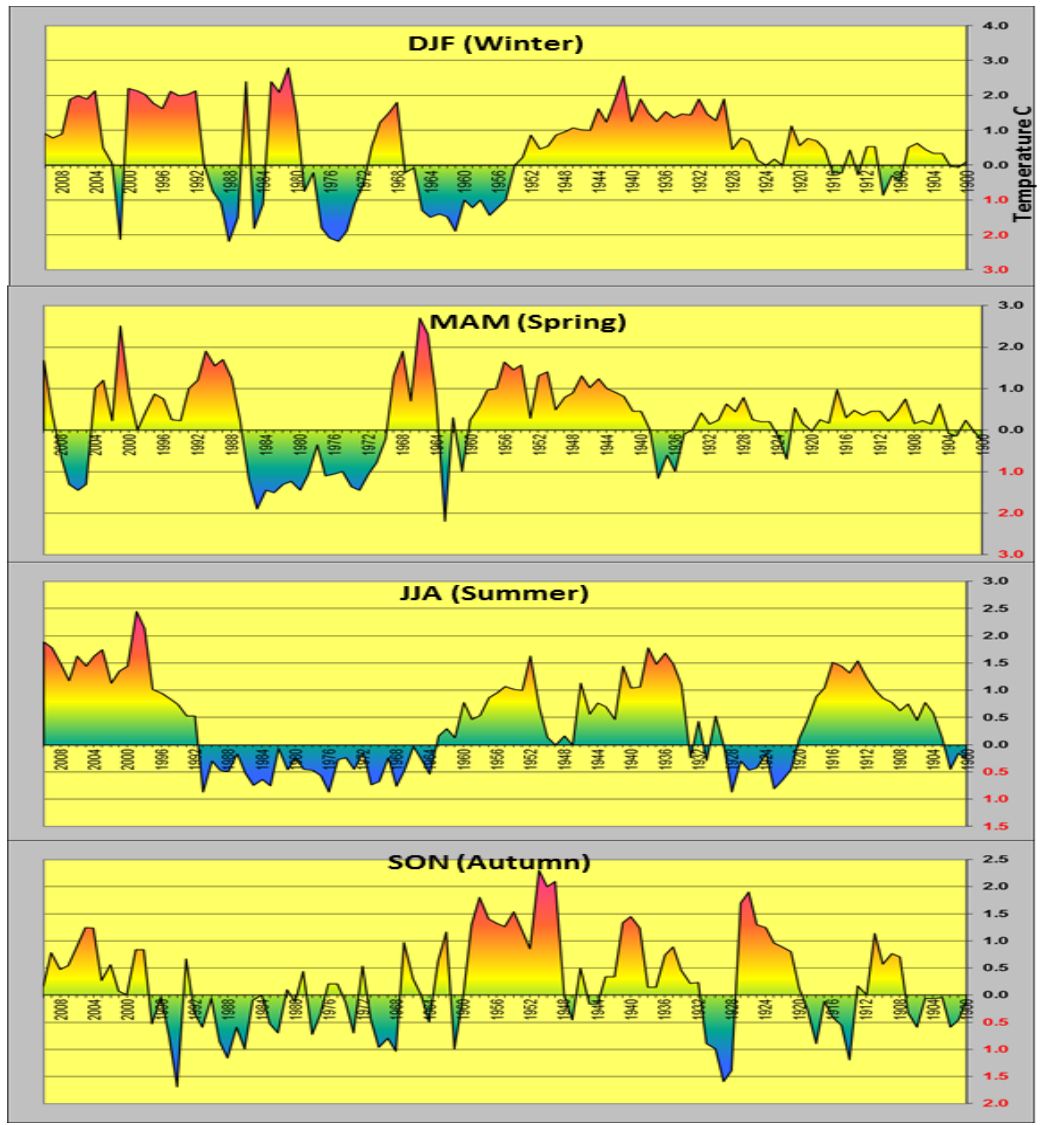

Figure 3. Seasonal temperature anomalies ordered as winter (DJF, upper panel), spring (MAM), summer (JJA) and autumn (SON, lower panel) (main period 1940-2000) in the Egypt for the period 1900-2014. 
Finally, the variability of autumn temperatures shows a first period of warming between 1932 and 1960 followed by a decreasing of temperatures until 1996 (the coldest autumn of the time-series). The last warming period began in 1998 and prolonged until 2014 in spite of this warmer period was not constant across time.

\subsection{Annual and Seasonal Rainfall Variability}

Generally, three rainfall belts may be distinguished: (1) The Mediterranean coastal belt, (2) middle Egypt with latitude $30^{\circ} \mathrm{N}$ as its southern boundary, and (3) upper Egypt. The first and second belts have a winter rainfall (Mediterranean regime); the rainy season extends from November to April, though mainly concentrated in December and January. These belts correspond roughly to the attenuated (shorter dry period) and accentuated (longer dry period) arid provinces of northern Egypt, where the average annual rainfall ranges from 100 to $150 \mathrm{~mm}$ in the attenuated arid province, and from 20 to $100 \mathrm{~mm}$ in the accentuated arid province. It extends rather south along the Gulf of Suez to Lat $26^{\circ} \mathrm{N}$ due to the orographic influence of the Red Sea coastal mountains. The third belt is almost rainless; it corresponds roughly to the hyper arid provinces. Rain in this belt is not an annually recurring incident; $10 \mathrm{~mm}$ may occur once every ten years.

The rainfall increases gradually to the North until it reaches about 20 $\mathrm{mm}$ at the borders with the arid province (at Giza). One of the major features of rainfall in arid and semi-arid regions [N.B. hyperarid (P/ETP< 0.03) and arid $(\mathrm{P} / \mathrm{ETP}=0.03-0.20)$ where $\mathrm{P}=$ precipitation and $\mathrm{ETP}=$ potential evapotranspiration, calculated by Penman's formula] other than being scanty, is its great temporal variability, average deviation of annual precipitation from the mean, expressed as percentage of the mean, is greatest in the hyper arid provinces (e. g. El Dakhla 83\%). In the arid province the percentage variability is $65 \%$ in Giza, which is close to the hyperarid provinces (FAO 2011).

Rainfall over Egypt is mainly of the showery type. Amounts may vary considerably from year to year, in the same place and may also differ widely in two neighboring localities in the same season or year. The rainy season, lasting from October to May, tends to start earlier in the north and west, since secondary Mediterranean air masses are most active in autumn, winter and spring, and generally follow west to east tracks. The dry season is almost totally rainless (Figure 4). Though occasional showers may fall over the Mediterranean coastal region in June or September, it is extremely rare for Rainfall to occur during July and August. 




Figure 4. Mean annual Rainfall in Egypt for the period 1947-2014.

Annual Rainfall anomalies for the whole period in Egypt are dominated by a high inter-annual variability accompanied by a slight increase statistically nonsignificant at the $95 \%$ level of $3.92 \mathrm{~mm} /$ decade. The linear trends computed for the seasonal rainfall anomalies show a non-significant increasing trend in winter and spring rainfall (at the 95\% level) while a non-significant decreasing trend is also detected in autumn rainfall (Table 4 and Figure 5).

Table 4. Linear trends (in ${ }^{\circ} \mathrm{mm} /$ decade) computed for annual and seasonal Rainfall in Egypt (1947-2014). The associated 95\% confidence intervals.

\begin{tabular}{|c|c|c|}
\hline Time-scale & $\begin{array}{c}\text { Linear trend } \\
\left({ }^{\circ} \text { C/decade) }\right.\end{array}$ & $\begin{array}{c}\mathbf{9 5 \%} \text { confidence } \\
\text { intervals }\end{array}$ \\
\hline DJF (Winter) & $\mathbf{6 . 1 2}$ & $(0.899 / 0.174)$ \\
\hline MAM (Spring) & $\mathbf{1 1 . 4}$ & $(2.166 / 0.190)$ \\
\hline SON (Autumn) & $\mathbf{- 1 3 . 6}$ & $(-2.053 / 0.151)$ \\
\hline Annual & $\mathbf{3 . 9 2}$ & $(0.6076 / 0.155)$ \\
\hline
\end{tabular}

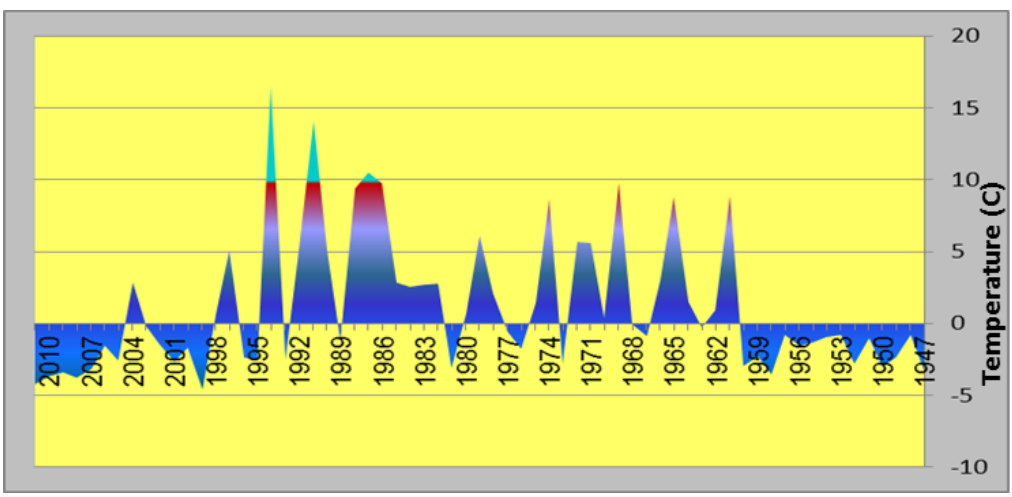

Figure 5. Annual Rainfall anomalies in Egypt for the period 1947-2014. 
This is consistent with Trenberth et al. (2007), who did not detect a generalized and a significant decrease of precipitation in the Mediterranean basin North and South. Other studies which dealt the evolution of the Rainfall during the $20^{\text {th }}$ century or before concluded annual Rainfall does not show appreciable changes in secular time scale (Lana \& Burgueño, 2000; Llasat \& Quintas, 2004; Saladié, 2004; Barrera-Escoda, 2008; Clivar, 2014; Joan Ramon, 2013 and Rita Man, 2013).

As occurred in annual Rainfall, seasonal anomalies show a very high variability among years in all seasons except spring during all time-series long (Figure 6). The variability of the winter rainfall is based on the dominance of dry winters from 1947 to 1960 , followed by a wetter period from 1960-1965, followed by a balanced combination of dry and wet winters between 1966 and 1982. Wetter conditions dominated in 1974s and 1978s, and from 1982-1992, while dry winters came back in 1980s, and from 1998-2014.
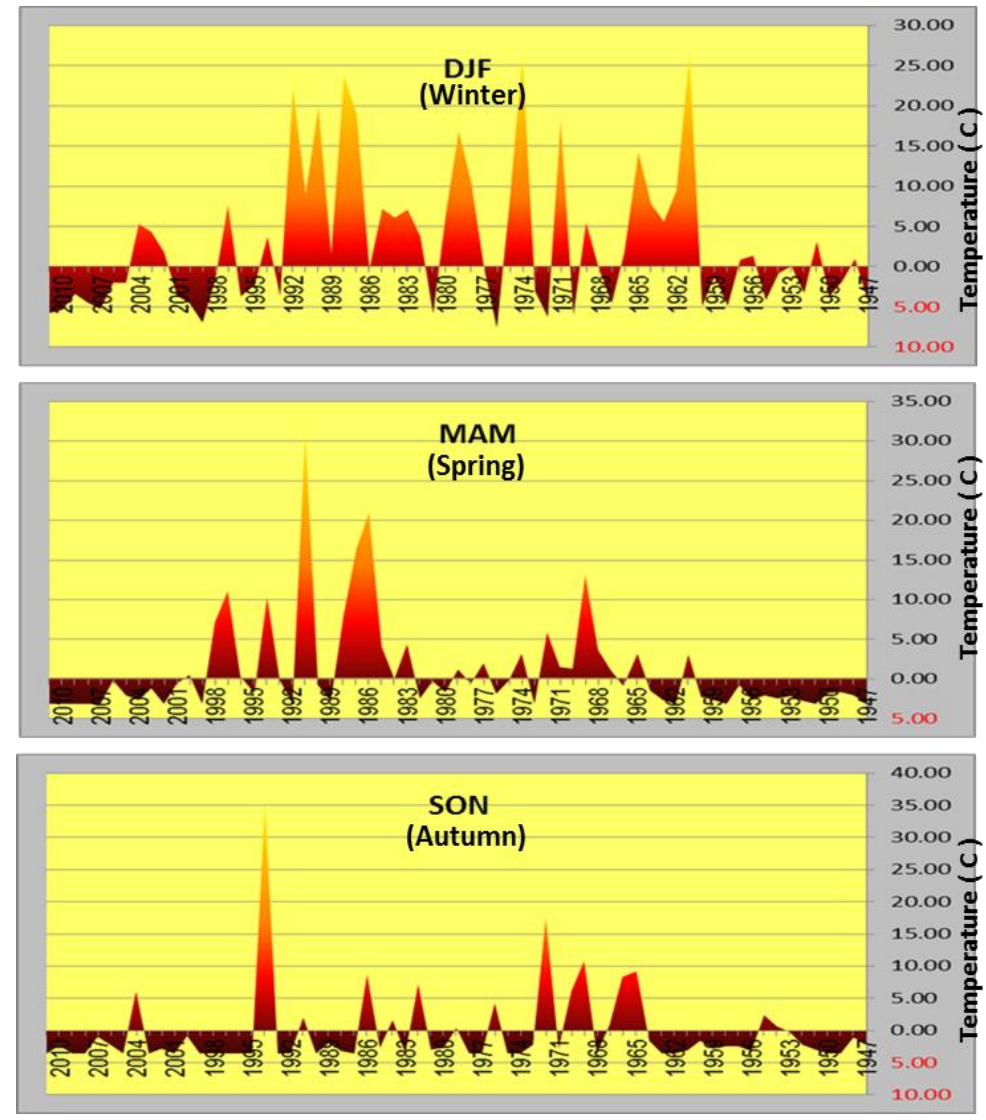

Figure 6. Seasonal precipitation anomalies ordered as winter (DJF, upper pannel), spring (MAM) and autumn (SON, lower pannel) in Egypt for the period 1947-2014. 
The variability of spring rainfall shows a balanced distribution of wet and dry springs during most of the time-series, it could be divided into three main periods, two periods of dry from 1947-1965 and from 2000-2014, separated by a wetted spring from 1983-1997. Moreover, although the dominance of wet springs was between mid-1965s and early-1974s while dry springs were focused from early-1947s to late-1964s, and from the period 2000-2014.

Finally, the variability of autumn rainfall is based on the dominance of dry conditions in all time-series under investigation 1947-2014, separated by scattered wet periods in mid-1965 to 1972 , early-1996 to 1999 , in 2004s, while the last two decades of the time-series were dominated by dry conditions (Figure 6).

\subsection{Drought Trends}

The current research was used the C3 software, Quality control and homogenization and climate data from The Centre for Climate Change (C3), University Rovira Virgili (Tarragona, Spain) http://www.c3.urv.cat/ last visit 20/05/2016. We analysed the spatial variability of the Pc-PDSI, SPI and SPEI over Egypt using principal component analysis (PCA). We obtained a classification of homogeneous areas according to the general temporal and spatial patterns of monthly rainfall and temperature along the 1961-2014 periods.

The most relevant droughts are identified and validated using documental sources. To ensure the quality of our results, the calibration of drought indices is checked. Afterwards, a trend analysis is carried out for the whole region under study as well as for each location individually in order to find out significant fluctuations in drought conditions. Furthermore, the role of temperature in drought indices is also assessed to quantify the effect of global warming on drought trends. Finally, we study the evolution of the drought spatial coverage across time.

Trends in the seasonal (DJF, MAM, JJA and SON) 6 and 12-month December (which is a summary of annual drought severity) SC-PDSI, SPI and SPEI series for particular stations, and trends in the series representative of different regions obtained through the PCA, were calculated using the Mann-Kendall $\boldsymbol{\tau}$ rank correlation coefficient (Kendall, 1955).

Figure (7) shows the evolution of the 6 and 12 months Sc-PDSI, SPI and SPEI derived from the regional series of rainfall, temperature and climatic 
water balance (P-ETo) for Egypt. Short time scales showed higher temporal frequency than long time scales. Nevertheless, independent of the drought time scale, the various time series showed a similar temporal behavior. The main drought episodes occurred in the 1998s, and from 2008 to 2010. In contrast, the period from 1966 to 1975 was dominated by humid conditions, evident in both the SPI and the SPEI.

Drought variability according to Sc-PDSI 6-Month (Figure 7) shows wet conditions from the period 2000-2015. Moreover, dry conditions are found in early-1971s, most of the 1975s and 1981s, mid-1985s, early-mid-1987, late1998 , most of the last two decades of the time-series in which the driest conditions were identified over Egypt from the period 1998 to 2014. Note that extremely dry conditions (less or equal than -3 in PDSI categories) are identified only in 1982 for the whole Egypt (regional average) while extremely wet conditions (greater or equal than +3 in PDSI categories) are not found in the time-series.
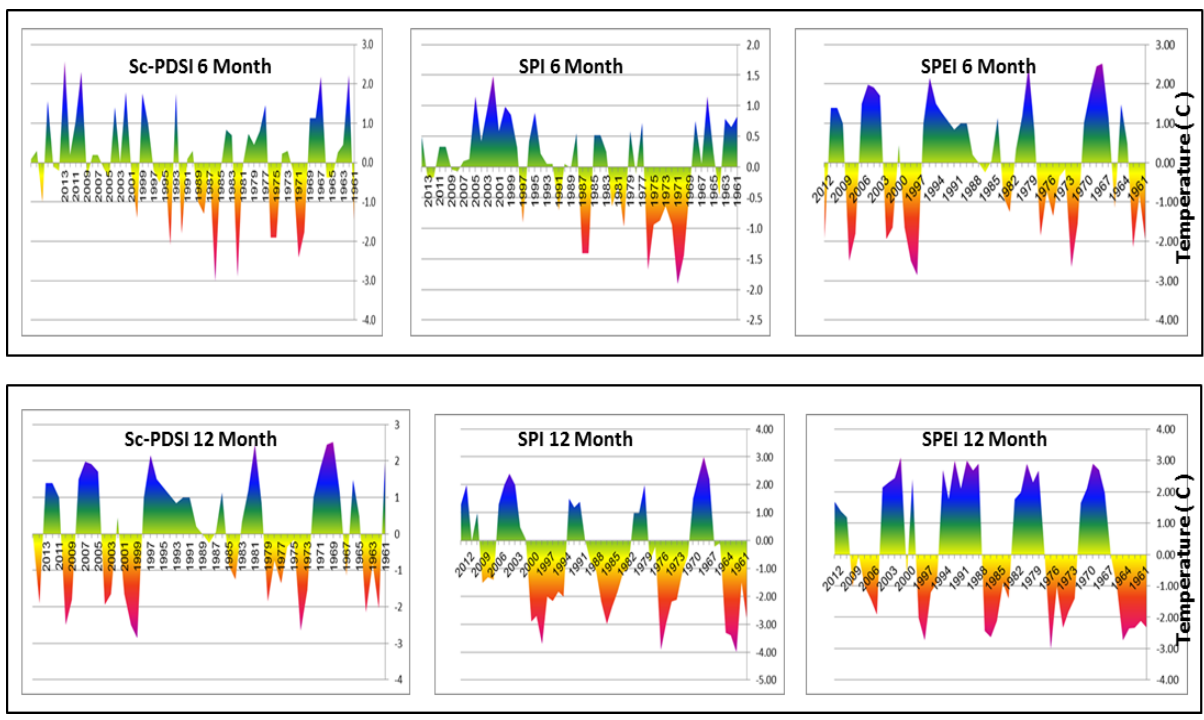

Figure 7. Evolution of the Sc-PDSI, SPI and SPEI at 6 and 12 Month time scale from 1961 to 2014.

Evidently, Drought variability according to 12 -month Sc-PDSI shows higher frequency of wet and dry condition, the wet condition for the period 1988-1998. Moreover, dry conditions are detected in late-1961 to the early1965, all the period from 1973 to1980, all the period from 1998 to 2003, and mutual condition from dry and wet from the period 2004-2015. 
Drought variability according to 6-month SPI (Figure 7) shows higher frequency of wet and dry conditions than Sc-PDSI time-series, but wet conditions are detected in late-1968s, early and late-1981s, early and late1987. Furthermore, dry conditions are found in mid-1961s to the mid of 1986s, the periods from 1979 to 1983 and 1999-2007 respectively. Drought variability according to 12-month SPI shows higher frequency of the wet and dry condition, the wet conditions are found in early-1962s, the period from 1973 to 1979, late-1994s, mid-1999s to end-2004, late-2009s and early-2014. On the other hand, the dry conditions are detected in mid-1966s, the period from 1968 to 1972 , the period from 1981 to early-1984s, mid-1987s, the period from 1989 to 1998 , and late-2013s.

Drought variability according to 6-month SPEI (Figure 7) shows wet conditions in late-1960s, the period from 1970 to the mid-1979s, early-1997s to the late-2003s, early-2006s to 2009, and late-2012s. Dry conditions are found in most of the 1964s and 1966s, late-1967 to late-1970s, mid-1978s, late-1995s, the period from 1988 to 1997, the period from 2004 to the late2006s, and mid-2011. Extremely dry conditions (less or equal than -2 in SPEI categories) are identified in 1968 and in 1978 respectively, while extremely wet conditions (greater or equal than +2 in SPEI categories) are not found in 1997. On the other hand, Drought variability according to 12-month SPEI (Figure.) shows higher frequency of the wet and dry condition, the wet conditions from 1961 to $1964,1973-1976$ and 1985-1988. The dry conditions are from 1967-1970, 1979-1982, 1988-1994, and 2000-2005.

\subsection{Terra-MODIS/NDVI Analysis}

Seasonal mean of NDVI and rainfall were used to quantify the change of NDVI and rainfall in comparison to the long-term seasonal mean of 20002016. Figures (8), (9) and (10) show the results from NDVI (2000-2016). Depending on the degree of change, a suggestion for classification of drought impact is found in (Table 5). In the following paragraphs, more descriptions about the percentage of change for each location are given:

Table 5. Degree of drought depends on the percent of change for NDVI only.

\begin{tabular}{|l|l|}
\hline \multicolumn{1}{|c|}{ Value } & \multicolumn{1}{c|}{ Degree of Drought } \\
\hline$>=0 \%$ & No drought \\
\hline$-1 \%$ to $-10 \%$ & Mild \\
\hline$-11 \%$ to $-20 \%$ & Moderate \\
\hline$-20 \%$ to $-30 \%$ & Severe \\
\hline$<-30 \%$ & Extreme \\
\hline
\end{tabular}



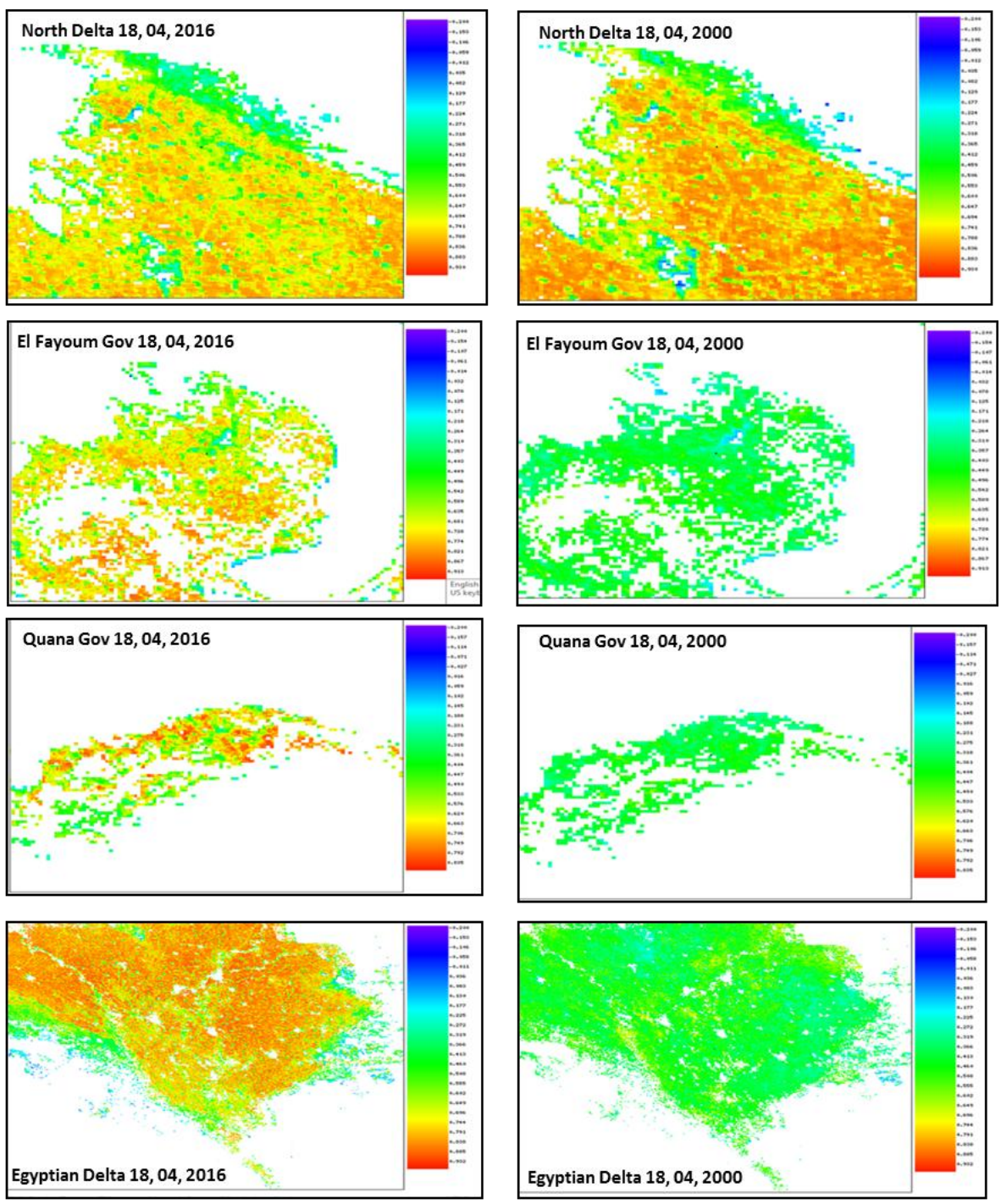

Figure 8. NDVI scale factor, filter, and land cover mask applied over Egypt from the period 2000-2016

\section{Egyptian Delta region:}

Climatically, it belongs to the Mediterranean region, includes the East, North and West delta, located in a semi-dry zone in the north of Egypt, where rainfall patterns showed that the two seasons were not clearly separated or there were only one long season in some years. Changes in rainfall showed that this region receives a different amount of rainfall every season. Egyptian Delta experienced drought in some seasons like in 2002, 2010 and 2012, 
when rainfall decrease to $25 \%$ less than normal, while in years 2004, 2013 and 2016, the region received a significant amount of rainfall. NDVI did not show any a severe or an extreme drought, but there was moderate drought in 2008. In 2016 greenness increased by $45 \%$ when the there was a significant amount of rainfall up to $70 \%$ more than the average in the first season.

El Dakhla Oasis: located in the Southwest in the hyper dry zone and it received the lowest amount of rainfall among all the locations. Results from NDVI changes indicated a severe drought in seasons of 2000, 2002, 2004, 2005, 2008 and 2016 with negative change $42 \%, 30 \%, 25 \%, 41 \%, 45 \%$ and $35 \%$, respectively. Changes in rainfall proved NDVI results in 2008 with negative change $52 \%$. In 2016, there was a negative change in rainfall with $55 \%$ and NDVI showed change with 50\%.


Figure 9. Mean grouped by Year and Month of NDVI over Egypt from the period 2000-2016

Sinai region: located in North West of Egypt, it belongs to the Mediterranean region, with semi-arid climate. NDVI results indicated that there was an extreme drought in the Years of 200, 2008, 2010 and 2016, and a severe drought in the Year of 2012 with 30\%, 25\%, 25\% and 19\% below the average, respectively. Rainfall results proved the result of NDVI in 2008 and 2010 with negative change of $15 \%$ and $35 \%$, respectively. 
El Fayoum Governorate: located in the semi-arid zone in southwest of Cairo. Rainfall appeared to be less changeable than NDVI except in the last five seasons. NDVI indicated an extreme drought in the second seasons of 2008 and 2010 with negative change $30 \%$ and $40 \%$, respectively. Rainfall indicated drought in the second seasons of 2010 and the first season of 2012 with negative change $25 \%$ and $33 \%$, respectively.

Assiut and Aswan Governorate: located in the semi-arid zone in the south of Egypt and it received the lowest amount of rainfall. Rainfall fluctuated from year to year, but this did reflect in NDVI pattern which might be due to the type of vegetation, which tends to be moderate. Results of NDVI indicated an extreme drought in the season of 2008 and severe drought in the first season of 2010. The highest record of negative change in rainfall was in the second season of 2002 and the first season of 2016 with $-35 \%$ to $42 \%$, respectively.
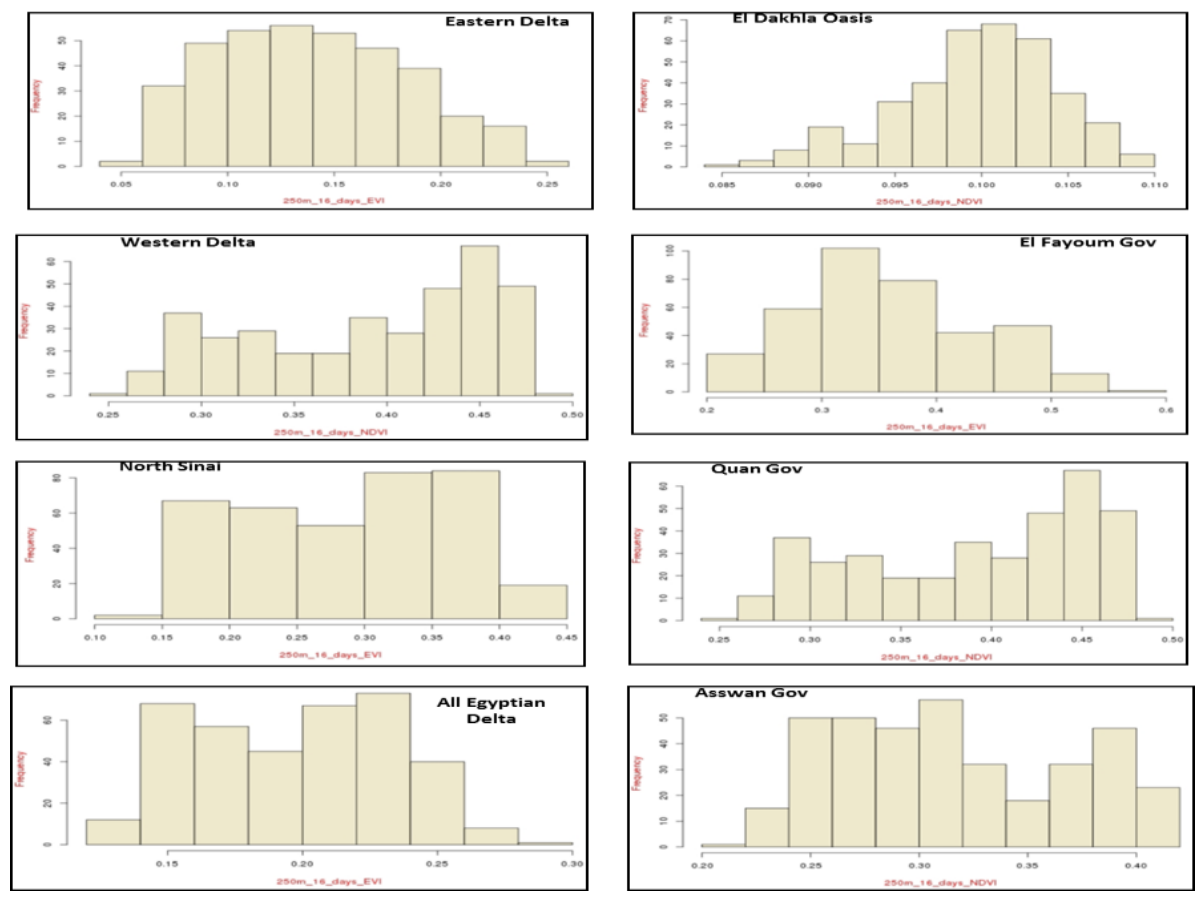

Figure 10. NDVI Frequency of subset area mean values over Egypt from the period 2000-2016. 


\section{Conclusions}

In this study, we investigate the climate variability across Egypt is described in terms of temperature and rainfall at annual and seasonal time-scale. Then, we discuss the drought variability, which is approached by the application of the most widely used drought indices (Sc-PDSI, SPEI and the SPI) over Egypt (1940 to 2014). A trend analysis is carried out on drought time-series in order to understand the behavior of drought conditions using Terra-MODIS NDVI to evaluate the Utilizing MODIS NDVI satellite data, GIS and Drought Indices for effective near real-time drought monitoring over Egypt.

Rainfall data are only required to compute SPI, but potential evapotranspiration (PET) is also needed to perform the Sc-PDSI and SPEI, which is estimated using the Thornthwaite's method. A Principal Component Analysis is carried out to identify spatial-temporal patterns of droughts and the characteristics and trends of severity, magnitude and duration of droughts and wet events are also described.

A remote sensing data proved to be a significant tool in monitoring and detecting drought components. In the thesis's case where rainfall data and other meteorological data were absent or unreliable, remote sensing data were the only practical choice. A comparison between different drought indices based on remote sensing shows that there are none of the major indices is inherently superior to the rest in all circumstances but some indices have advantages spatially. There is still need for a comprehensive study to evaluate the performance of these drought indices, especially in semiarid and arid zone because of the frequent occurrence of drought.

The superiority of NDVI is that: it is easy to calculate and used; provided relatively freely to users and cover the entire globe. The areas with low NDVI values doesn't necessary mean that drought occurred there: the index's value can be also associated with an early harvest or with the lack of vegetation due to various regions.

MODIS NDVI data have many advantages spatially and temporally in comparison to rainfall data which make it more practical. The spatial resolution of NDVI is 0.05 degrees ( $\sim 5600$ meters) and RE rainfall data is 0.1 degrees, which is higher than any kind of rainfall data available in this case (CRU rainfall data is only 0.5 degrees).

It is common to find that two months without precipitation can produce drought conditions in the soil moisture suffering meteorological and/or agricultural drought. But, this lack of precipitation probably will not have an immediate effect on the discharge of large river systems, or in the level of water stored in the reservoirs of a region. However, the opposite situation can also occur. 


\section{LIST OF ABBREVIATIONS}

AWC: Available Water Content of the soil

CLIVAR: Climate Variability and Predictability Organization

CRU: Climate Research Unit, University of East Anglia

C3: Centre for Climate Change, Universitat Rovira i Virgili

ENSO: El Niño Southern Oscillation

IPCC: Intergovernmental Panel on Climate Change

ITCZ: I n ter tropical Convergence Zone

LP DAAC: Land Processes Distributed Active Archive Center MOD12C1: MODIS Land cover

MODIS: Moderate Resolution Imaging Spectroradiometer

NDVI: Normalized difference vegetation index

PET: Potential Evapotranspiration

PDSI: Palmer's Drought Severity Index

Sc-PDSI: Self-Calibrating Palmer's Drought Severity Index

SPEI: Standardized Precipitation-Evapotranspiration Index

SPI: Standardized Precipitation Index

WMO: World Meteorological Organization 


\section{REFERENCES}

- Allen RG, Pereira LS, Raes D, Smith M. 1998. Crop evapotranspiration guidelines for computing crop water requirements. FAO Irrigation and Drainage Paper 56, FAO, Rome.

- $\quad$ Blenkinsop, S. and H.J. Fowler, 2007a. Changes in drought frequency, severity and duration for the British Isles projected by the PRUDENCE regional climate models. Journal of Hydrology, 342, 50-71.

- Brando PM. 2010. Seasonal and interannual variability of climate and vegetation indices across the Amazon. Proc. Natl. Acad. Sci. U. S. A.107: 14685-14690.

- Brando PM, Balch JK, Nepstad DC, Morton DC, Putz FE, Coe MT, Silvério D, Macedo MN, Davidson EA, Nobrega CC, Alencar A, Soares-Filho BS. 2014. Abrupt increases in Amazonian tree mortality due to drought-fire interactions. Proc. Natl. Acad. Sci. U. S. A. 111: 6347-6352.

- $\quad$ Burke, E. J., Brown S. J. 2008. Evaluating uncertainties in the projection of future drought.2008. J. Hydrometeorol. 9, 292-299.

- Cao, L., T. Liu, and L. Wei. 2014. "A Comparison of Multi-Resource Remote Sensing Data for Vegetation Indices." IOP Conference Series: Earth and Environmental Science 17: 012067.doi:10.1088/1755-1315/17/1/012067.

- $\quad$ Chapin, F. S., A. J. Bloom, C. B. Field, and R. H. Waring. 1987. "Plant-Responses to Multiple Environmental-Factors." Bioscience 37 (1): 49-57. doi:10.2307/1310177.

- Contreras S. C., 2003. Importancia de las sequías en el clima de México. Pp. 1-7 http://www.uaslp.mx/Docs/CCSYH/Programas/publicaciones/sequia.pdf

- Dai, A, 2011. Characteristics and trends in various forms of the Palmer Drought Severity Index (PDSI) during 1900_2008. J. Geophys. Res. 116, D12115.

- Dai A. 2013. Increasing drought under global warming in observations and models. Nat. Clim. Change 3: 52-58.

- Dai A, 2014. Drought under global warming: a review. WIREs Clim Chang 2:4565. doi:10.1002/wcc.81

- Ding Y, Hayes MJ, Widhalm M ,2014: Measuring economic impacts of drought: a review and discussion. Papers in Natural Resources. Paper 196. http://digitalcommons.unl.edu/natrespapers/196

- Domroes, M., and El-Tantawi, A., 2005: recent temporal and spatial temperature changes in EGYPT, INTERNATIONAL JOURNAL OF CLIMATOLOGY, Int. J. Climatol. 25: 51-63.

- Droogers P, Allen RG. 2002. Estimating reference evapotranspiration under inaccurate data conditions. Irrig. Drain. Syst. 16: 33-45.

- El-Tantawi, A., 2005: Climate Change in Libya and Desertification of Jifara Plain Using Geographical Information System and Remote Sensing Techniques, Doktor der Naturwissenschaften, Mainz, Germany.

- Escurra JJ, Vazquez V, Cestti R, De Nys E, Srinivasan R. 2014. Climate change impact on countrywide water balance in Bolivia. Reg. Environ. Change 14: 727742.

- Estrada P. M., 2001. Cambio climático global: causas y consecuencias. http://www.inigi.gob.mx/inegi/contenidos/espanol/prensa/contenidos/articulos/amb ientales/climatico.pdf 
- Garcia M, Raesb D, Jacobsenc S-E, Micheld T. 2007. Agroclimatic constraints for rain-fed agriculture in the Bolivian Altiplano. J. Arid Environ. 71: 109-121.

- Hasanean HM. 2004. Wintertime surface temperature in Egypt in relation to the associated atmospheric circulation. International Journal of Climatology 24: 985999.

- Heino R. 1994. Climate in Finland During the Period of Meteorological Observations, Finnish Meteorological Institute Contributions12. Academic Dissertation: Helsinki, 209.

- Hayes, M., D. A. Wilhite, M. Svoboda, and O. Vanyarkho, 1999: Monitoring the 1996 drought using the standardized precipitation index. Bull. Amer. Meteor. Soc., 80, 429-438.

- Hayes MJ, 2012. Drought indices, National Drought Mitigation Center (http://www.drought.unl.edu/whatis/indices.htm). With modifications by Dev Niyogi and Umarporn Charusambot, Indiana State Climate Office, Purdue University (http://iclimate.org/ 2.2.2012).

- Heim, R. R., 2002: A review of twentieth-century drought indices used in the United States. Bull. Amer. Meteor. Soc., 83, 1149-1165.

- Hunt ED, Svoboda M, Wardlow B, Hubbard K, Hayes M, Arkebauer T. 2014. Monitoring the effects of rapid onset of drought on non-irrigated maize with agronomic data and climate-based drought indices. Agric. For. Meteorol. 191: 111.

- $\quad$ IPCC climate change 2012. Managing the Risks of Extreme Events and Disasters to Advance Climate Change Adaptation. A Special Report of Working Groups I and II of the Intergovernmental Panel on Climate Change [Field, C.B., V. Barros, T.F. Stocker, D. Qin, D.J. Dokken, K.L. Ebi, M.D. Mastrandrea, K.J. Mach, G.-K. Plattner, S.K. Allen, M. Tignor, and P.M. Midgley (eds.)]. Cambridge University Press, Cambridge, UK, and New York, NY, USA, 582.pp.

- Jansen M, Schulze A, Werding L, Streit B. 2009. Effects of extreme drought in the dry season on an anural community in the Bolivian Chiquitano region. Salamandra 45: 233-238.

- $\quad$ Khan, S., H. F. Gabriel, and Rana, T, 2008: Standard precipitation index to track drought and assess impact of rainfall on watertables in irrigation areas. Irrig. Drain. Syst., 22, 159-177.

- Karavitis CA, Alexandris S, Tsesmelis DE, Athanasopoulos G ,2011. Application of the Standardized Precipitation Index (SPI) in Greece. Walter J 3:787-805. doi:10.3390/w3030787

- Kenny P, 2008. Assessment of the social impacts of drought and government and non-government social support services. Issues Paper. http://www.daff.gov.au/_data/assets/pdf_file/0004/

710644/social_panels_isues_paper.pdf

- Li, Y.J.; Zheng, X.D.; Lu, F. and Ma, J, 2012. Analysis of drought evolvement characteristics based on Standardized Precipitation Index in the Huaihe River Basin. Proced. Eng, 28, 434-437.

+ Mendivelso HA, Camarero JJ, Gutiérrez E and Zuidema PA. 2014. Timedependent effects of climate and drought on tree growth in a neotropical dry forest: short-term tolerance vs. long-term sensitivity. Agric. For. Meteorol. 188: 13-23. 
- $\quad$ Mastrandrea, M. D., C.B. Field, T.F. Stocker, O. Edenhofer, K.L. Ebi, D.J. Frame, H. Held, E. Kriegler, K.J. Mach, P.R. Matschoss, G.-K. Plattner, G.W. Yohe, and F.W. Zwiers, 2014. Guidance Note for Lead Authors of the IPCC Fifth Assessment Report on Consistent Treatment of Uncertainties. Intergovernmental Panel on Climate Change (IPCC). Available at <http://www.ipcc.ch>.

- McKee, T. B., N. J. Doesken, and Kleist, J. 1993. The relationship of drought frequency and duration to time scales. Preprints, Eighth Conf. on Applied Climatology. Anaheim, CA, Amer. Meteor. Soc., 179-184.

- Motha, R., and W. Baier. 2005. Impacts of Present and Future Climate Change and Climate Variability on Agriculture in the Temperate Regions: North America, Climatic Change, 70(1), 137-164.

- Magaña R. J., Pérez L, Conde C, Gay C, Medina S. 1997. El fenómeno de El Niño y la Oscilación del Sur (ENOS) y sus impactos en México. Departamento de Meteorología General. Centro de Ciencias de la Atmosfera.

- Nicholson SE, Tucker CJ, Ba MB. 1998. Desertification, drought and surface vegetation: an example from the west African Sahel. Bull. Am. Meteorol. Soc. 79: 815-829.

- Lee, R., F. Yu, K. P. Price, J. Ellis, and P. Shi. 2002. "Evaluating Vegetation Phenological Patterns in Inner Mongolia Using NDVI Time-Series Analysis." International Journal of Remote Sensing 23 (12): 2505-2512. doi:10.1080/ 01431160110106087.

- Palmer, W.C. Meteorological Drought; White R.M., Ed, 1965.; U.S. Weather Bureau: Washington, DC, USA.

- Phillips OL, Araggo LEOC, Lewis SL, Fisher JB, Lloyd J, Lopez-GonzJlez G, Malhi Y, Monteagudo A, Peacock J, Quesada CA, Van Der Heijden G, Almeida S, Amaral I, Arroyo L, Aymard G, Baker TR, B Jnki O, Blanc L, Bonal D, Brando P, Chave J, De OliveiraxCA, Cardozo ND, Czimczik CI, Feldpausch TR, Freitas MA, Gloor E, Higuchi N, Jiménez E, Lloyd G, Meir P, Mendoza C, Morel A, Neill DA, Nepstad D, Patiwo S, Peouela MC, Prieto A, Ramerez F, Schwarz M, Silva J, Silveira M, Thomas AS, Steege HT, Stropp J, Vgsquez R, Zelazowski P, Dgvila EA, Andelman S, Andrade A, Chao K-J, Erwin T, Di Fiore A, Honorio EC, Keeling H, Killeen TJ, Laurance WF, Cruz AP, Pitman NCA, Vargas PN, Ramerez-Angulo H, Rudas A, Salam॰o R, Silva N, Terborgh J, Torres-Lezama A. 2009. Drought sensitivity of the amazon rainforest. Science 323: 1344-1347.

- Potop, V.; Mozny, M, and Soukup, J, 2012. Drought evolution at various time scales in the lowland regions and their impact on vegetable crops in the Czech Republic. Agric. Forest Meteorol. 2012, 156, 121-133.

- Rita Man Sze Yu, 2013. European Droughts under Climate Change:Projections and Uncertainties, Submitted to the University of East Anglia for the degree of Doctor of Philosophy

- Roman-Cuesta RM, Carmona-Moreno C, Lizcano G, New M, Silman M, Knoke T, Malhi Y, Oliveras I, Asbjornsen H, and Vuille M. 2014. Synchronous fire activity in the tropical high Andes: an indication of regional climate forcing. Glob. Change Biol. 20(6): 1929-1942.

- Seiler C, Hutjes RWA an Kabat P. 2013a. Climate variability and trends in Bolivia. J. Appl. Meteorol. Climatol. 52: 130-146. 
- Seiler C, Hutjes RWA and Kabat P. 2013b. Likely ranges of climate change in Bolivia. J. Appl. Meteorol. Climatol. 52: 1303-1317.

- $\quad$ Seiler C, Hutjes RWA, Kruijt B, Quispe J, Adez S, Arora VK, Melton JR, Hickler $\mathrm{T}$ and Kabat P. 2014. Modeling forest dynamics along climate gradients in Bolivia. J. Geophys. Res. Biogeosci. 119: 758-775.

- Serrano A, Garcdda AJ, Mateos VL, Cancillo ML, Garrido J. 1999. Monthly modes of variation of precipitation over the Iberian Peninsula. J. Clim. 12: 28942919.

- Shahid S, Behrawan H, 2008. Drought risk assessment in the western part of Bangladesh. Nat Hazards J 46:391-413. doi:10.1007/ s11069-007-9191-5.

- Sheffield J., Wood, EF., Roderick ML., 2012. Little change in global drought over the past 60 years. LETTER DOI: 10.1038/nature11575.

- Spinoni, J.; Naumann, G.; Carrao, H.; Barbosa, P. and Vogt, J, 2014. World drought frequency, duration, and severity for 1951-2010. Int. J. Climatol. 2014, 34, 2792-2804.

- Szinell Cs., Bussay, A., and Szentimrey, T., 1998, Drought tendencies in Hungary. Int. J. Climatol. 18, 1479-1491.

- Thornthwaite C. W., 1948. An approach toward a rational classification of climate. Geographical Review, 38, 55-94.

- Tao J, Zhongfa Z, Shui C, 2011. Drought monitoring and analyzing on typical karst ecological fragile area based on GIS. Procedia Environ Sci 10:2091-2096. Published by Elsevier Ltd. Selection. doi:10.1016/j.proenv.2011.09.326. Available online at www.sciencedirect.com

- UN Secretariat General, 1994. United Nations convention to combat drought and desertification in countries experiencing serious droughts and/or desertification, particularly in Africa. Paris

- Thornthwaite, C.W., 1948: An approach toward a rational classification of climate. Geogr. Rev., 38, 55-94.

- Vicente-Serrano SM. 2006. Differences in spatial patterns of drought on different time scales: an analysis of the Iberian Peninsula. Water Resour. Manage. 20: 37-60.

- Vicente-Serrano SM, Beguera S, Lopez-Moreno JI, Garcea-Vera MA, Stepanek P. 2010a. A complete daily precipitation database for North-East Spain: reconstruction, quality control and homogeneity. Int. J. Climatol. 30: 1146-1163.

- Vicente-Serrano SM, Beguerea S, Lopez-Moreno JI. 2010b. A multi-scalar drought index sensitive to global warming: the Standardized Precipitation Evapotranspiration Index - SPEI. J. Clim. 23: 1696-1718.

- Vicente-Serrano SM, Beguerea S, Lopez-Moreno JI. 2011. Comment on "Characteristics and trends in various forms of the Palmer Drought Severity Index (PDSI) during 1900-2008” by A. Dai. J. Geophys. Res. Atmos. 116: D19112, doi: 10.1029/2011JD016410.

- Vicente-Serrano SM, Zouber A, Lasanta T, Pueyo Y. 2012a. Dryness is accelerating degradation of vulnerable shrublands in semiarid Mediterranean environments. Ecol. Monogr. 82: 407-428.

- Vicente-Serrano SM, Beguerea S, Lorenzo-Lacruz J, Camarero JJ, Lopez-Moreno JI, Azorin-Molina C, Revuelto J, Moron-Tejeda E, Sanchez-Lorenzo A. 2012b. Performance of drought indices for ecological, agricultural and hydrological applications. Earth Interact. 16: 1-27. 
- Vicente-Serrano SM, Lopez-Moreno J-I, Beguera S, Lorenzo-Lacruz J, SanchezLorenzo A, Garca-Ruiz JM, Azorin-Molina C, Revuelto J, Trigo R, Coelho F, Espejo F. 2014. Evidence of increasing drought severity caused by temperature rise in southern Europe. Environ. Res. Lett. 9: 044001, doi: 10.1088/17489326/9/4/044001.

- Wang, G. L, 2005. Agricultural drought in a future climate: Results from 15 global climate models participating in the IPCC 4th assessment. Clim. Dynam. 25, 739753.

- Wilhite, D., and M. Glantz .1985. Understanding: the Drought Phenomenon: The Role of Definitions, Water International, 10(3), 111-120.

- Wilhite, D. A., 1993: Drought Assessment, Management, and Planning: Theory and Case Studies. Natural Resource Management and Policy Series, Vol. 2, Kluwer, 293 pp.

- World Meteorological Organization, 2012: Standardized Precipitation Index User Guide (M. Svoboda, M. Hayes and D. Wood). (WMO-No. 1090), Geneva.

- Wu,H.,M.D.Svoboda,M. J.Hayes,D.A.Wilhite, andF.Wen, 2007: Appropriate application of the Standardized Precipitation Index in arid locations and dry seasons. Int. J. Climatol., 27, 65-79.

- Xie, N.M.; Xin, J.H.; Liu, S.F, 2014. China's regional meteorological disaster loss analysis and evaluation based on grey cluster model. Nat. Hazards 2014, 71, 10671089. 